정규논문(Regular Paper)

방송공학회논문지 제 17 권 제5호, 2012년 9월 (JBE Vol. 17, No. 5, September 2012)

http://dx.doi.org/10.5909/JBE.2012.17.5.817

ISSN 1226-7953(Print)

$$
\begin{aligned}
& \text { 이동형 패럴랙스 배리어 모바일 } 3 \mathrm{D} \text { 디스플레이를 위한 강인한 시청자 } \\
& \text { 시역 위치 추정 알고리즘 } \\
& \text { 김 기 석 }{ }^{a)} \text {, 조 재 수 }{ }^{\ddagger} \text {, 엄 기 문 }{ }^{b}
\end{aligned}
$$

\title{
Robust Viewpoint Estimation Algorithm for Moving Parallax Barrier Mobile 3D Display
}

\author{
Giseok Kim ${ }^{\text {a) }}$, Jae-Soo Cho ${ }^{\text {a) }}$, and Gi-Mun $\mathrm{Um}^{\text {b) }}$
}

요 약

본 논문에서는 이동형 패럴랙스 배리어 방식의 모바일 $3 \mathrm{D}$ 디스플레이를 위해 급격한 조명 변화에도 강인한 시청자 시역위치 추정 알고리즘을 제안한다. 기존의 비올라-존스 검출기와 옵티컬-플로우를 선형 결합한 시역 위치 추정 알고리즘[1]은 급격하게 조명이 변하 는 경우 잘못된 시역 위치를 추정하는 문제가 있음을 확인하였고, 특히 이러한 급격한 조명의 변화 문제는 모바일 환경에서 흔히 발생 하는 환경조건이다. 그리고 어두운 공간에서 $3 \mathrm{D}$ 디스플레이를 시청하는 경우 디스플레이 조명이 시청자의 얼굴에 비치기 때문에 조명 변화가 매우 크게 발생할 수 있다. 급격한 조명의 변화에 대한 문제점을 해결하기 위해 본 논문에서는 매 프레임마다 정확하게 옵티컬 -플로우 얼굴 검출기의 정확도를 판단할 수 있는 방법을 새롭게 제안하고, 다양한 실험을 통해 그 효과를 검증한다. 조명의 변화등에 의해 옵티컬-플로우가 잘못된 추적 결과를 출력하는 경우, 기존의 두 알고리즘(비올라-존스 얼굴검출기+옵티컬-플로우 특징점 추적기) 을 선별적으로 선택함으로써 강인한 얼굴검출 및 추적이 이루어지도록 하고, 다양한 실험 결과를 통해 그 효과를 검증한다.

\begin{abstract}
This paper presents a robust viewpoint estimation algorithm for Moving Parallax Barrier mobile 3D display in sudden illumination changes. We analyze the previous viewpoint estimation algorithm that consists of the Viola-Jones face detector and the feature tracking by the Optical-Flow. The sudden changes in illumination decreases the performance of the Optical-flow feature tracker. In order to solve the problem, we define a novel performance measure for the Optical-Flow tracker. The overall performance can be increased by the selective adoption of the Viola-Jones detector and the Optical-flow tracker depending on the performance measure. Various experimental results show the effectiveness of the proposed method.
\end{abstract}

Keyword : 3D vision, Viewpoint estimation, Face detection and tracking, Optical-flow, Viola-Jones detector

a) 한국기술교육대학교 컴퓨터공학부 (Korea University of Technology and Education, School of Computer Science and Engineering)

b) 한국전자통신연구원 방송시스템연구부(Electronics and Telecommunications Research Institute(ETRI), Broadcasting System Research Department)

‡ Corresponding Author : 조재수 (Jae-Soo Cho)

E-mail: jaesoo27@koreatech.ac.kr

Tel: +82-41-560-1491 Fax: +82-41-560-1462

※ 본 연구는 방송통신위원회의 ETRI 연구개발지원사업인 “무안경 다시점 3D지원 UHDTV 방송 기술 개발”과제(KCA-2012-11921-02001)의 연구 결과로 수행되었습니다.

Manuscript received May 4, 2012 Revised July 16, 2012 Accepted August 20, 2012 


\section{I. 서 론}

최근 3D 영상에 대한 사회적, 문화적 관심이 증가하면서 이를 위한 $3 \mathrm{D}$ 디스플레이 장치가 빠르게 보급되고 있다. 특히 특수한 안경을 착용해야만 하는 안경식 3D 디스플레 이 장치 뿐 아니라 안경이 없이 시청이 가능한 무안경식 $3 \mathrm{D}$ 디스플레이가 게임기, 휴대폰 등의 모바일 기기를 중심 으로 보급되고 있다. 무안경식 $3 \mathrm{D}$ 디스플레이의 가장 큰 단점은 좁은 시야각이다. $3 \mathrm{D}$ 디스플레이 장치로부터 정확 히 정면에서 미리 정해진 거리에 시선을 위치해야 정확한 $3 \mathrm{D}$ 시청이 가능하다. 이를 해결하기 위해 디스플레이 장치 에서 발산되는 빛의 각도를 자유자재로 조절할 수 있는 방 법이 다양하게 개발되고 있으며, 그 중에 대표적인 방법이 그림 1과 같은 이동형 패럴랙스 배리어 방식(moving parallax barrier) ${ }^{[2]}$ 이다. 이동형 패럴랙스 배리어 방식은 배리어 이동 기술을 통해 입체를 느낄 수 있는 시청영역을 변환할 수 있는 기술이다. 기존 패럴랙스 배리어 방식은 시청자가 정해진 위치를 벗어나면 입체감을 느낄 수 없는 문제점을 가지고 있다. 이를 해결하기 위한 방안으로 개발된 이동형 패럴랙스 배리어 방식은 시청자가 이동하는 경우 시선을 추적하는 기술을 이용하여 시청자의 위치를 감지한 후, 해 당 위치에서 입체감을 느낄 수 있도록 배리어를 이동해주 도록 한다. 이를 위해서는 시청자의 시역 위치를 계측하는 방법이 필수적으로 요구된다.

시청자의 시역위치를 판단하기 위해서는 일반적으로 카 메라를 이용하여 시청자의 얼굴을 검출하는 알고리즘을 사
용한다. 영상 센서를 이용한 얼굴 검출 알고리즘으로 가장 대표적인 것은 비올라-존스 얼굴 검출 방법 ${ }^{[3]}$ 이다. 비올라존스 얼굴 검출 방법은 사람의 얼굴이 정면을 향하고 있는 환경에서는 빠른 검출 속도와 매우 좋은 검출율을 보이지 만, 주변 조명의 밝기와 빛의 방향에 영향을 크게 받고, 얼 굴이 조금이라도 기울어지는 경우 얼굴을 검출하지 못하는 심각한 문제점이 있다. 즉 정해진 좁은 얼굴 각도에 대해서 만 얼굴 검출이 가능하기 때문에 자유로운 모바일 시청자 의 움직임과 다양한 조명 변화에 대처할 수 없는 문제점이 있다. 또 비올라-존스 얼굴검출 알고리즘은 연속적인 얼굴 검출 정보를 전혀 사용하지 않고, 단지 한 장의 입력영상에 서만 얼굴의 존재 여부를 판단하기 때문에 안정적으로 얼 굴이 검출되지 않고, 얼굴의 중심도 매 프레임마다 미세하 게 흔들리는 문제점이 있다. 이러한 문제점들을 극복하기 위해 선행연구 ${ }^{[1]}$ 에서는 그림 2 와 같이 비올라-존스 얼굴 검출기와 옵티컬-플로우 ${ }^{[4][5]}$ 에 의한 특징점 추적 알고리즘 을 결합한 새로운 시역계측 알고리즘을 제안하였다. 하지 만 기 제안된 알고리즘의 경우, 급격한 조명의 변화에 옵티 컬-플로우에 의한 특징점 정합이 제대로 되지 않아 시역계 측 알고리즘의 정확도가 매우 낮아지는 단점을 가지고 있 음을 다양한 실험과정에서 확인되었다. 본 논문에서는 이 러한 급격한 조명의 변화 문제점을 해결하는 개선된 시역 계측 알고리즘을 제안하고자 한다.

본 논문의 남은 장은 다음과 같이 구성된다. 먼저 2 장에 서는 기존의 선행 연구에서 제안된 시역 계측 알고리즘을 분석하여 급격하게 조명이 변하는 환경에서 발생할 수 있
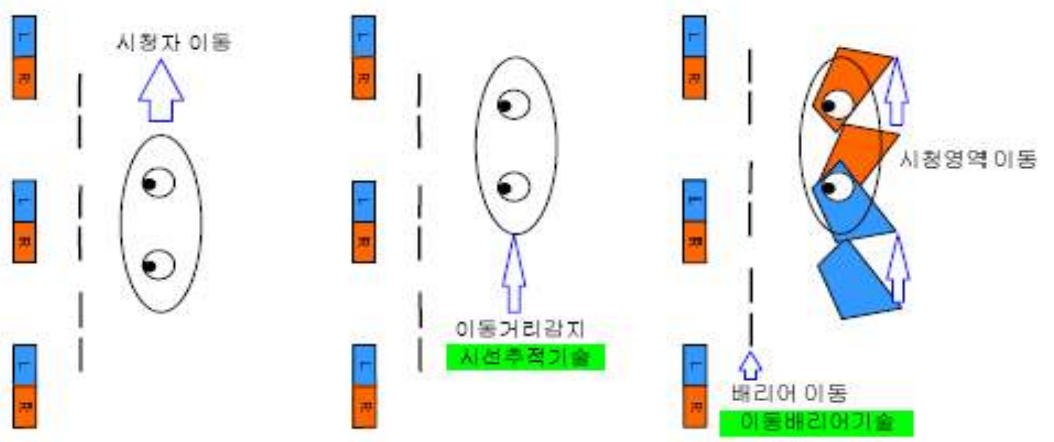

그림 1. 이동형 디중 패럴랙스 배리어 방식의 3D 디스플레이

Fig. 1. Moving Parallex Barrier mobile 3D display 
는 문제점을 분석한다. 3 장에서는 문제 해결을 위한 다양 한 방법을 제시한다. 수정된 검출기의 실행 결과 및 분석을 4 장에서 제시하고, 마지막 5 장에서 결론 및 추후 연구 방 안에 대해서 논한다.

\section{II. 기존 시역 계측 알고리즘 ${ }^{[1]}$ 의 문제점 분석}

비올라-존스 얼굴 검출기와 옵티컬-플로우 특징점 추적 기를 활용한 선행연구 시역 계측 알고리즘의 전체적인 순

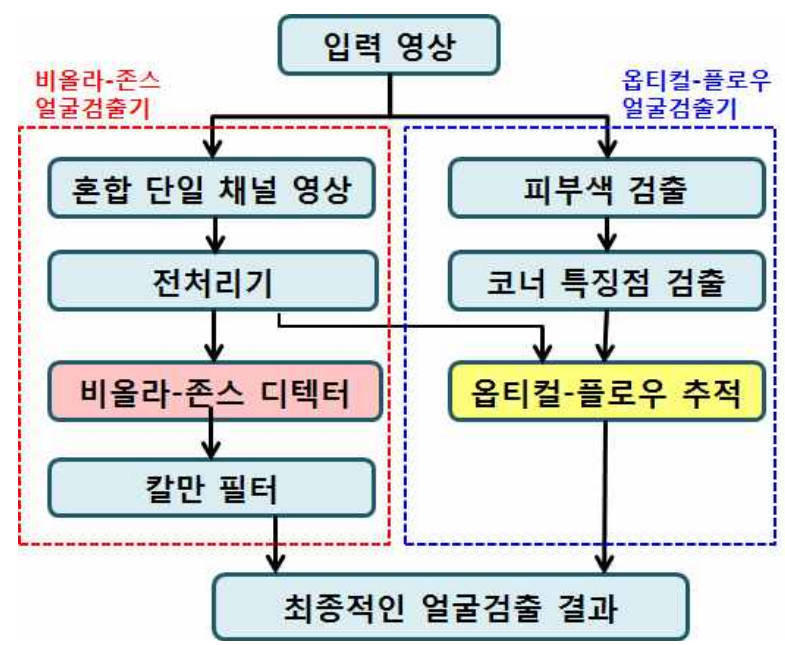

그림 2. 선행연구[1]에서 개발된 시역 계측 알고리즘

Fig. 2. The viewpoint estimation algorithm of the previous work[1]

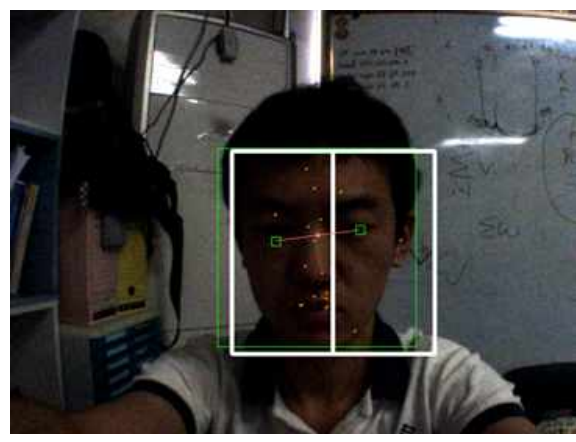

(a) $t$ 프레임
서도를 그림 2에 나타내었다. 비올라-존스 검출기가 가지고 있는 문제점을 극복하기 위해 옵티컬-플로우 특징점 검출 및 추적기를 함께 활용했다. 다음 표 1 은 각각의 알고리즘 의 장단점에 대하여 정리한 결과를 나타낸다.

표 1. 선행연구[1]에서 개발된 시역 계측 알고리즘 장단점 분석 Table 1. Pros and Cons of the previous viewpoint estimation algorithm

\begin{tabular}{|c|c|c|}
\hline $\begin{array}{c}\text { 얼굴 검출 } \\
\text { 방법 }\end{array}$ & \multicolumn{1}{|c|}{ 장 점 } & \multicolumn{1}{|c|}{ 단 점 } \\
\hline $\begin{array}{c}\text { 비올라-존스 } \\
\text { 얼굴 검출기 }{ }^{[3]}\end{array}$ & $\begin{array}{l}\text { 초기 입력영상에서 } \\
\text { 실시간으로 얼굴을 검출 할 } \\
\text { 수 있음 }\end{array}$ & $\begin{array}{l}\text { - 얼굴이 약간 기울어지는 } \\
\text { 경우 얼굴을 검출하지 못함 } \\
\text { - 이전에 추출된 얼굴정보를 } \\
\text { 전혀 사용하지 않음 }\end{array}$ \\
\hline $\begin{array}{c}\text { 옵티컬-플로우 } \\
\text { 특징점 추적 } \\
\text { 얼굴 검출기 }\end{array}$ & $\begin{array}{l}\text { 얼굴이 기울어져도 얼굴을 } \\
\text { 검출하고, 추적할 수 있음 } \\
\text { 이전에 추출된 얼굴정보를 } \\
\text { 상함 }\end{array}$ & $\begin{array}{l}\text { 조명이 급격하게 변하거나 } \\
\text { 얼굴이 가려지는 상황에서 } \\
\text { 특징점 추적이 잘못되는 } \\
\text { 경우 발생 } \\
\text { 이전 프레임의 잘못된 } \\
\text { 결과가 누적되는 경우 발생 }\end{array}$ \\
\hline
\end{tabular}

표 1에서 분석한 결과와 같이 비올라-존스 얼굴 검출기는 얼굴의 기울기에 따라 검출 성능이 저하되며, 특히 이전 영 상의 얼굴검출 결과를 전혀 반영하지 않기 때문에 실제 실 험에서 얼굴이 검출되지 않는 경우가 빈번이 발생한다. 옵 티컬-플로우 얼굴 검출기는 이전 프레임의 결과를 반영하 기 때문에 얼굴 기울기에 강인한 특성을 갖지만, 특징점 기 반의 추적으로 인해 그림 3과 같이 급격하게 조명이 변화하 거나 영상의 얼굴 영역이 가려지는 상황이 발생할 경우, 잘

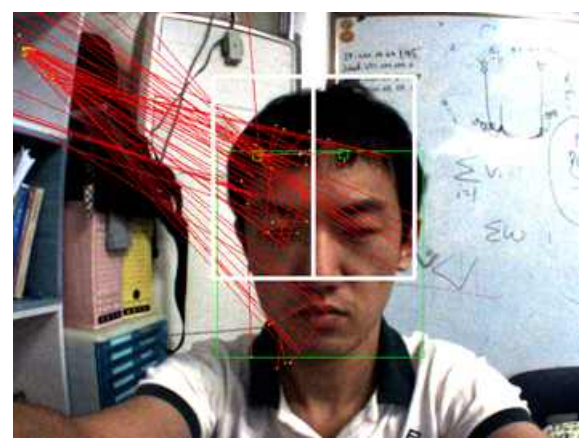

(b) $t+1$ 프레임

그림 3. 급격한 조명변화에서 옵티컬-플로우 얼굴추적기의 문제점(흰색 사각창: 옵티컬-플로우에 의한 얼굴 검출 결과, 초록색 사각창. 비올라-존스에 의한 얼굴검출 결과, 빨간색 선: 옵티컬-플로우에 의한 얼굴 특징점 추적 결과)

Fig. 3. A problem of the optical-flow tracker in sudden illumination change(white rectangle: optical-flow, green rectangle: Viola-Jones, red lines: face feature points tracked by the optical flow) 
못된 추적 결과를 출력하게 된다. 또한 옵티컬-플로우가 단 독으로 활용될 경우 이전 프레임의 실패 결과가 다음 프레 임으로 누적될 수 있다. 이러한 상호간의 단점을 극복하고 장점을 극대화하기 위해 선행연구[1]에서는 식 (1)과 같은 선형 결합 방법을 사용하여 얼굴검출 및 추적 성능을 높일 수 있었다.

$$
R(x, y)=\alpha \cdot V J(x, y)+(1-\alpha) \cdot O F(x, y)
$$

여기서, $R(x, y)$ 는 최종적으로 도출된 얼굴 검출 결과의 중심 좌표값이며, $V J(x, y)$ 와 $O F(x, y)$ 는 각각 비올라-존스 얼굴 검출기에 의한 결과와 옵티컬-플로우 추적에 의한 얼 굴검출 결과의 얼굴 중심 좌표를 의미한다. $\alpha$ 는 두 알고리 즘의 결과를 선형 조합하기 위한 파라미터로 0 과 1 사이의 값을 가진다. 만약 얼굴 검출에 있어서 비올라-존스 알고리 즘의 결과가 정확하다면 $\alpha$ 는 큰 값으로 설정하며, 옵티컬플로우의 결과가 더 정확하다면 $\alpha$ 를 작은 값으로 설정한다.

$$
O F_{t}(x, y)=R_{t-1}(x, y)+\frac{\sum_{i=1}^{N} \mathrm{v}_{i}}{N}
$$

식 (2)는 $N$ 개의 옵티컬-플로우 벡터 $V=\left\{\mathrm{v}_{1}, \mathrm{v}_{2}, \ldots \mathrm{v}_{N}\right\}$ 가 주어졌을 때, $t$ 프레임의 옵티컬-플로우 결과 $O F_{t}(x, y)$ 가 이전 $t-1$ 프레임의 최종 결과 $R_{t-1}(x, y)$ 로부터 도출됨 을 보여준다. $R_{t-1}(x, y)$ 는 $V J_{t-1}(x, y)$ 의 결과를 반영하기 때문에 최종 결과 $R_{t}(x, y)$ 는 $O F(x, y)$ 결과 보다는 $V J(x, y)$ 의 결과에 수렴하게 된다. 즉, $\alpha$ 가 0 으로만 설정되 지 않는다면, 옵티컬-플로우의 잘못된 결과가 누적되는 단 점을 극복할 수 있다.

본 알고리즘에서는 선형 결합의 가중치를 나타내는 $\alpha$ 가 매우 중요한 위치를 차지한다. $\alpha$ 가 크면 비올라-존스 얼굴 검출기에 대한 의존도가 커지기 때문에 얼굴의 움직임에 대한 다이내믹스(dynamics)에 더욱 민첩하게 대처할 수 있
지만, 비올라-존스 얼굴검출기가 가지는 미세한 떨림 현상 과 같은 불안정성 때문에 기존의 이동형 $3 \mathrm{D}$ 패럴랙스 배리 어 디스플레이 경계지역에서는 안좋은 결과를 초래한다. 반대로 $\alpha$ 가 너무 작아서 옵티컬-플로우에 대한 의존도가 커지면 얼굴의 움직임을 정밀하게 따라갈 수 있지만, 얼굴 이 손으로 가려지는 등 옵티컬-플로우의 실패가 발생하는 경우, 다시 비올라-존스 검출기의 결과로 수렴하는데 매우 오랜 시간이 걸린다. 특히 기존 연구 결과는 그림 3 처럼 조 명의 밝기가 심하게 바뀌면서 옵티컬-플로우 검출기의 결 과가 매우 부정확한 경우가 문제가 되었다. 본 논문에서 제 안하는 기술의 최종 적용 대상인 모바일 단말 환경에서는 그림 3과 같이 어두운 곳에서 밝은 곳으로 이동하거나 차량 불빛과 같은 외부 요인에 의해서 조명 환경이 안정적이지 못한 상황이 빈번하게 발생할 수 있기 때문에 이에 강인한 얼굴검출 알고리즘이 필요하다. 그래서 본 논문에서는 옵 티컬-플로우의 결과에 대한 신뢰도를 판별하여 성능에 막 대한 영향을 줄 수 있는 $\alpha$ 를 상황에 맞게 조절할 수 있는 적응적인 알고리즘을 제안하고자 한다.

\section{III. 급격한 조명의 변화에 강인한 얼굴 검출 및 추적 알고리즘}

\section{1. 옵티컬-플로우 특징점 검출 정확성 검증}

본 논문에서는 옵티컬-플로우에 의한 얼굴 추적의 정확 성(또는 신뢰도)을 판별하기 위해 옵티컬-플로우에 의한 얼 굴 추적 실패율을 정의하고, 얼굴 검출 결과의 신뢰도를 판 단한다. 이를 위해 인접한 프레임의 두 입력 영상으로부터 추출한 옵티컬-플로우 벡터 $V=\left\{\mathrm{v}_{1}, \mathrm{v}_{2}, \ldots \mathrm{v}_{N}\right\}$ 에 대해 식 (3)에 따라 부정확한 특징점 벡터를 찾아내고, 찾아낸 불확 실한 특징점 벡터를 활용하여 식 (4)와 같은 옵티컬-플로우 에 의한 얼굴 추적 실패율 $\left(\eta_{t}\right)$ 을 새롭게 정의함으로써 옵티 컬-플로우에 의한 얼굴검출 결과를 판단하고자 한다. 식 (3)

$$
f\left(\mathrm{v}_{i}\right)=\left\{\begin{array}{ll}
1, & \text { if }\left|\mathrm{v}_{i}\right|<\text { threshold } \\
0, & \text { otherwise }
\end{array} \text { and } B_{i} \in \text { Face Region }\left(\mathrm{v}_{i}=A_{i} B_{i}\right)\right.
$$


의 조건에 의해 추적에 실패한 옵티컬-플로우 벡터 $\left(f\left(\mathrm{v}_{i}\right)=0\right)$ 로 판별된 경우에는 즉시 해당 특징점 벡터에 대 한 추적을 포기하고 다른 특징점을 선택하게 된다.

$$
\begin{aligned}
\eta_{t}= & \frac{\text { 잘못추적된특징점의 수 }}{\text { 모든 특징점의 수 }} \times 100(\%) \\
= & \frac{N-\sum_{i=1}^{N} f\left(\mathrm{v}_{i}\right)}{N} \times 100(\%)
\end{aligned}
$$

식 (3)에서 첫 번째 조건의 $\left|\mathrm{v}_{i}\right|$ 는 $i$ 번째 특징점의 옵티컬플로우 벡터 크기를 나타낸다. 즉, 개별 옵티컬-플로우 특징 점 벡터가 특정한 크기(threshold) 이상으로 나타날 경우 그 특징점 추적은 오류로 판별한다. 영상에서 프레임간의 시 간차에 의한 물리적 한계를 고려하여 임계값을 설정해야 한다. 밝기 값이 급격하게 변하는 상황에서는 옵티컬-플로 우 벡터가 터무니 없이 크게 나타나므로(그림 3.(b) 참조) 잘못된 특징점 벡터를 선별하는데 좋은 특징이 될 수 있다.

$B_{i}$ 는 옵티컬-플로우 벡터 $\mathrm{v}_{i}$ 의 머리(head)에 해당하는 좌 표, 즉 $t$ 영상의 특징점의 좌표를 의미하고, Face Region 은 이전 프레임의 최종 얼굴 검출 결과에 나타난 사각형의 얼 굴 영역을 뜻한다. 만약 옵티컬-플로우 벡터가 가리키는 좌 표가 기존의 얼굴 영역을 만히 벗어날 경우 해당 벡터는 오류로 간주한다. 대부분의 얼굴 움직임은 기존의 얼굴 위
치에서 크게 벗어나지 않으므로 합당한 조건이 된다. 더불 어 이 조건에 의해 얼굴 외곽의 특징점들이 기존의 얼굴 위치에서 벗어나면서 탈락하게 되는데, 보통 정면을 보고 있는 얼굴 중심 부근에서 비교적 정확한 옵티컬-플로우 추 적이 일어나게 되므로 부정확한 추적이 예상되는 외곽의 특징에 대한 추적을 미리 포기하는 효과를 가져올 수 있다.

식 (4)에 정의된 추적 실패율 $\left(\eta_{t}\right)$ 은 $t$ 프레임에서의 옵티 컬-플로우에 의한 얼굴 추적 실패율을 정의한 것으로, 옵티 컬-플로우에 의한 얼굴검출 결과의 신뢰도(또는 정확도)를 판단할 수 있는 근거로 사용할 수 있으며, 본 논문에서는 다음 식 (5)와 같이 옵티컬-플로우 얼굴 추적에 대한 최종적 인 검출 결론을 얻을 수 있다.

If $\eta_{t}>$ Threshold, then, theOptical Flow result is wrong.

(5)

그림 4는 화면의 밝기가 급격하게 변화하는 테스트 비디 오 시퀀스에 대한 옵티컬-플로우 얼굴 추적 실패율 $\left(\eta_{t}\right)$ 을 측정한 결과를 도시한 것이다. 그림에서 점선 부분으로 표 시된 영역은 화면의 전체 밝기가 급격하게 변화하는 구간 으로 옵티컬-플로우 얼굴 추적 실패율 $\left(\eta_{t}\right)$ 의 Threshold 값 을 약 50 으로 설정하게 된다면, 그림 4 의 왼쪽으로부터 첫 번째와 두 번째 영역에서는 옵티컬-플로우 추적 결과가 실 패하였음을 판단할 수 있고, 세 번째 영역에서는 비록 화면

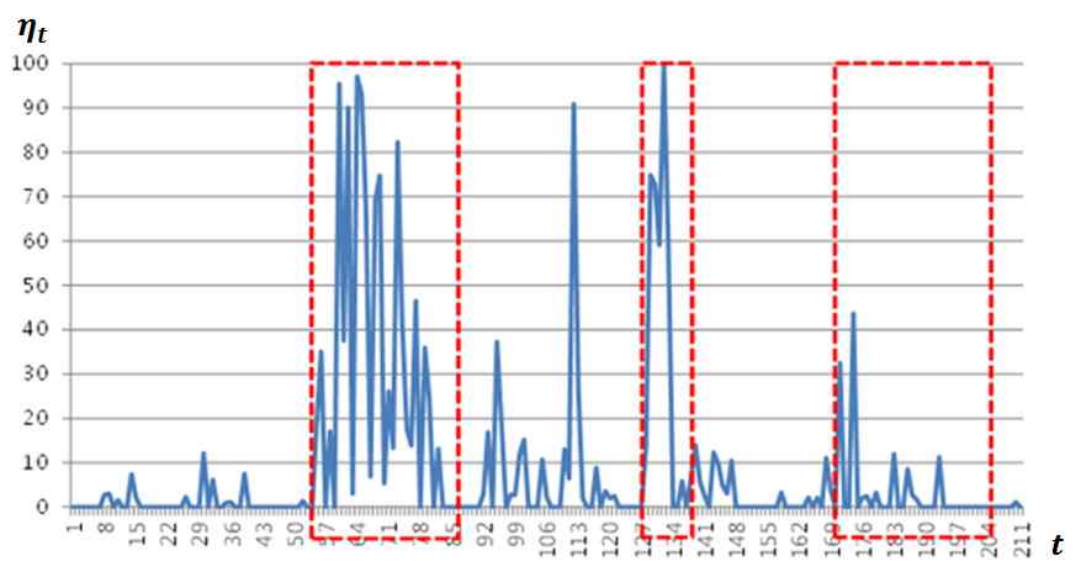

그림 4. 화면의 조명 밝기가 급격하게 변화하는 테스트 비디오 시퀀스에 대한 옵티컬-플로우 얼굴추적 실패율 $\left(\eta_{t}\right)$ 측정 결과

Fig. 4. Face tracking failure rate $\left(\eta_{t}\right)$ for a test video sequence with sudden illumination changes 
의 밝기가 급격하게 변하여도 옵티컬-플로우에 의한 얼굴 검출 및 추적결과가 성공하였음을 쉽게 판단할 수 있다.

\section{2. 개선된 시역계측 알고리즘}

본 논문에서 제안하는 개선된 새로운 시역계측 알고리즘 의 전체 블록도는 그림5와 같다. 기본적으로 선행 연구 ${ }^{[1]}$ 에 서 개발한 그림 2 의 알고리즘을 유지하면서, 최종적인 얼굴 검출 결과 부분에서 옵티컬-플로우에 의한 얼굴 검출 정확 도 판별 부분이 추가되었고, 옵티컬-플로우 추적 실패율 $\left(\eta_{t}\right)$ 을 근거로 비올라-존스 얼굴검출기와의 선형결합에 필요한

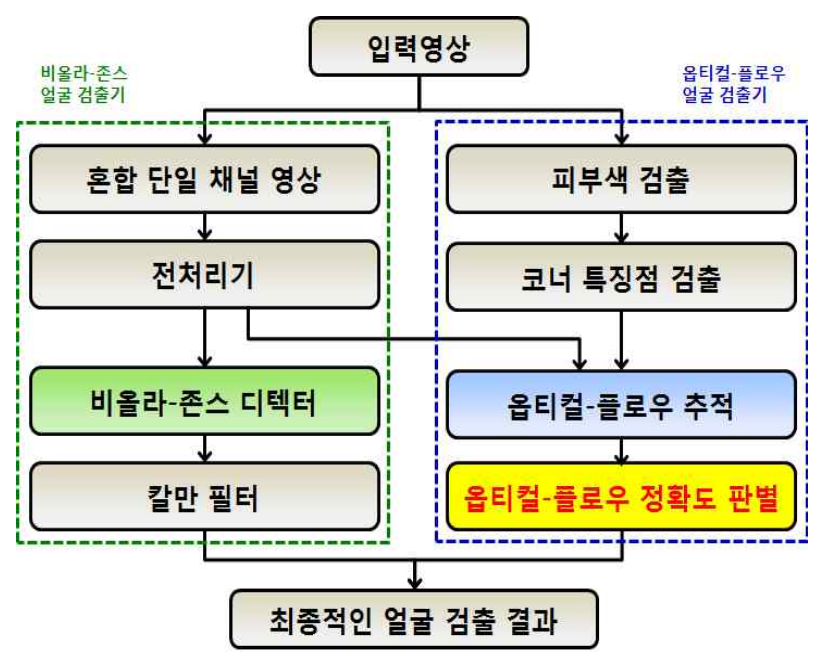

그림 5. 개선된 새로운 시역계측 알고리즘 전체 블록도

Fig. 5. The overall block diagram of the proposed viewpoint estimation algorithm

표 2. 최종적인 얼굴검출 및 추적 결과 (YES: 검출성공, NO: 검출 실패) Table 2. The final result of the face detection and tracking(YES: Success, NO: Failure).

\begin{tabular}{|c|c|c|}
\hline $\begin{array}{c}\text { 비올라-존스 } \\
\text { 얼굴검출기 }\end{array}$ & $\begin{array}{c}\text { 옵티컬-플로우 } \\
\text { 얼굴검출기 }\end{array}$ & $\begin{array}{c}\text { 최종적인 } \\
\text { 얼굴검출 및 추적 결과 }\end{array}$ \\
\hline YES & YES & $\begin{array}{c}(\text { 식 1)과 같은 선형결합 } \\
(\alpha=0.2)\end{array}$ \\
\hline YES & NO & $\begin{array}{c}\text { 비올라-존스 얼굴 검출 결과 } \\
(\alpha=1)\end{array}$ \\
\hline NO & YES & $\begin{array}{c}\text { 옵티컬-플로우 얼굴 검출 결과 } \\
(\alpha=0)\end{array}$ \\
\hline NO & NO & Kalman Filter 에 의한 얼굴예측 지점 \\
\hline
\end{tabular}

파라미터 $\alpha$ 값을 조절하여 각 얼굴 검출기의 효율을 극대 화 할 수 있는 방법을 고안한 것이다. 표 2는 각 얼굴 검출 기의 얼굴 검출 및 추적결과를 토대로 $\alpha$ 값을 정의한 내용 을 나타낸다.

첫 번째로 비올라-존스 얼굴검출기가 입력영상에서 얼굴 을 검출하는 것을 성공하고 동시에 옵티컬-플로우 얼굴 검 출기도 성공하는 경우 식 (1)과 같은 선형결합으로 최종 추 적결과를 도출한다. 여기서 $\alpha$ 값은 여러 차례 수행한 실험 결과를 근거로 $\alpha=0.2$ 로 설정하였다.

두 번째로 비올라-존스 얼굴 검출기는 검출에 성공하지 만, 옵티컬-플로우 얼굴 검출기는 검출에 실패하는 경우는 비올라-존스 얼굴 검출 결과만을 활용하게 된다. 이때는 $\alpha=1$ 이 되게 된다. 세 번째로 비올라-존스 얼굴 검출기로 는 얼굴 검출이 실패하고, 옵티컬-플로우 얼굴 검출기로는 검출이 성공하는 경우는 옵티컬-플로우 얼굴검출 결과를 활용하게 되며, 이 때 $\alpha$ 는 0 이 되게 된다. 마지막으로 두 얼굴 검출기 모두 얼굴 검출이 안되는 경우는 칼만 필터 (Kalman Filter)에 의한 예측 지점을 3D 디스플레이의 시점 으로 판단한다. 이를 정리하면 표 2와 같다.

여기서 사용되는 칼만 필터의 상태로 얼굴의 중심 좌표 및 가로 폭, 그리고 각각에 대한 속도 성분을 이용하며 각각 의 변수는 모두 독립인 것으로 가정한다. 세로 폭은 비올라존스의 특성에 의해 가로 폭과 일정한 비율로 유지되기 때 문에 칼만 필터의 상태값으로 유지할 필요가 없다. 여기서 주의할 점은 만약 칼만 필터 상태의 속도 성분이 0 이 아닐 경우, 얼굴을 검출하지 못하는 상태가 상당 기간 지속되면 얼굴이 영상 밖으로 벗어나는 일이 생길 수 있다는 것이다. 그러므로 칼만 필터의 이용은 매우 신중해야 하며, 제어에 대한 확신이 없다면 칼만 필터를 쓰는 대신 얼굴의 위치를 제자리에 두거나 바로 몇 프레임 내에 얼굴을 놓친 것으로 판별하는 것이 강인한 추적에 도움이 될 수 있다.

\section{IV. 실험 결과}

본 논문에서 제안한 얼굴 검출 방법을 검증하기 위해 두 가지 방법으로 실험을 진행했다. 먼저 일반적인 실내 환경 에서 얼굴 검출이 정확하게 이루어지는지를 확인하기 위해 
다양한 실험자들이 다양한 각도로 얼굴을 움직이면서 얼굴 검출 결과를 확인했다. 두 번째로는 조명 밝기가 급격하게 변하는 환경에서 선행연구 ${ }^{[1]}$ 의 결과와 비교하여 실험했다.

본 논문에 대한 구현은 인텔 $\mathrm{i} 5-760$ 프로세서에서 $640 \mathrm{x}$ 480 크기의 영상에 대해 약 $62 \mathrm{fps}$ (frame per second)의 처 리 속도를 보였다. 이는 비올라-존스 알고리즘의 검색 범위 를 얼굴 주변으로 제한하고 단 하나의 얼굴을 찾으면 곧바 로 검색을 종료하는 등의 최적화를 거친 것이다. 먼저 총 4명의 실험자에 대해서 얼굴을 다양하게 움직이면서, 정면 을 주시할 수 있는 상태를 유지하도록 주문했다. 또한 두 눈이 평행한 상태를 유지하도록 얼굴의 움직임을 제한했다.
이는 무안경신 스테레오 디스플레이를 제대로 시청할 때의 제약사항을 그대로 반영한 것이다. 이 때, 본 논문에서 제안 한 알고리즘은 단 1 프레임도 얼굴을 놓치지 않고 추적하는 $100 \%$ 의 성능을 보여주었다. 그림 6 은 실험자들의 다양한 움직임을 나타내며 그림 7은 실험자 한명이 추적되는 얼굴 만을 잘라내어 연속적으로 보여주고 있다.

추가적으로 급격한 조명 밝기에 대한 본 논문에서 제안 한 방법의 성능 평가를 위해 조명이 급격하게 변하는 환경 에서 얼굴검출 및 추적 결과를 다양하게 실험하였다. 피실 험자는 밝기가 급격하게 변하는 구간에서는 거의 정지한 상태를 유지하다가 밝기값이 안정적인 상황에서 좌우로 어

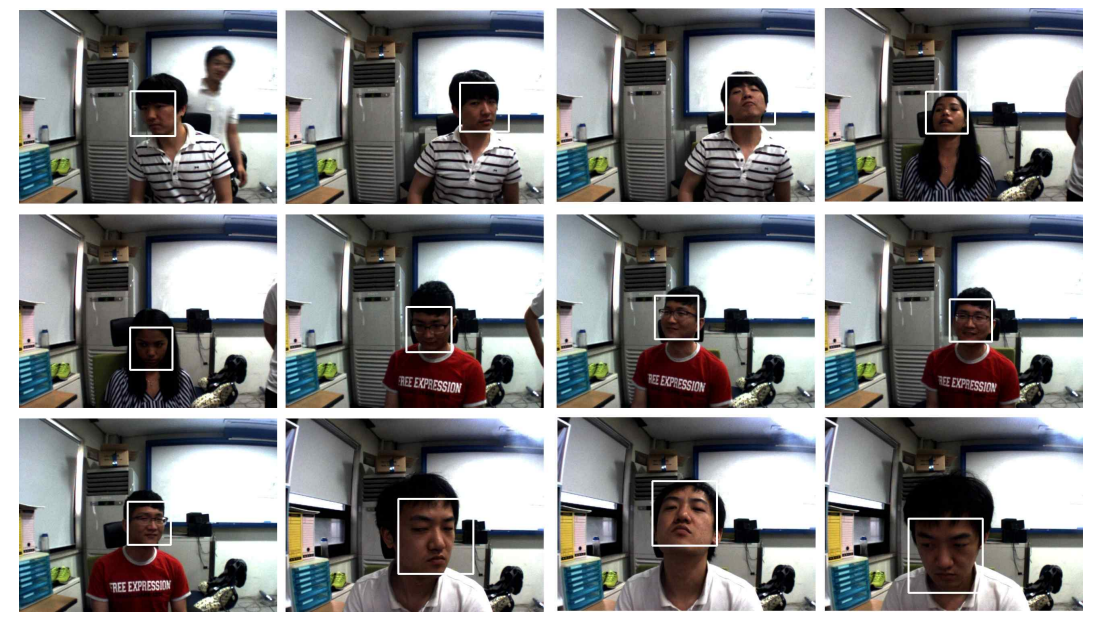

그림 6. 다양한 실험자들에 대한 얼굴 추적 실험 영상

Fig. 6. Various experimental results for different viewers

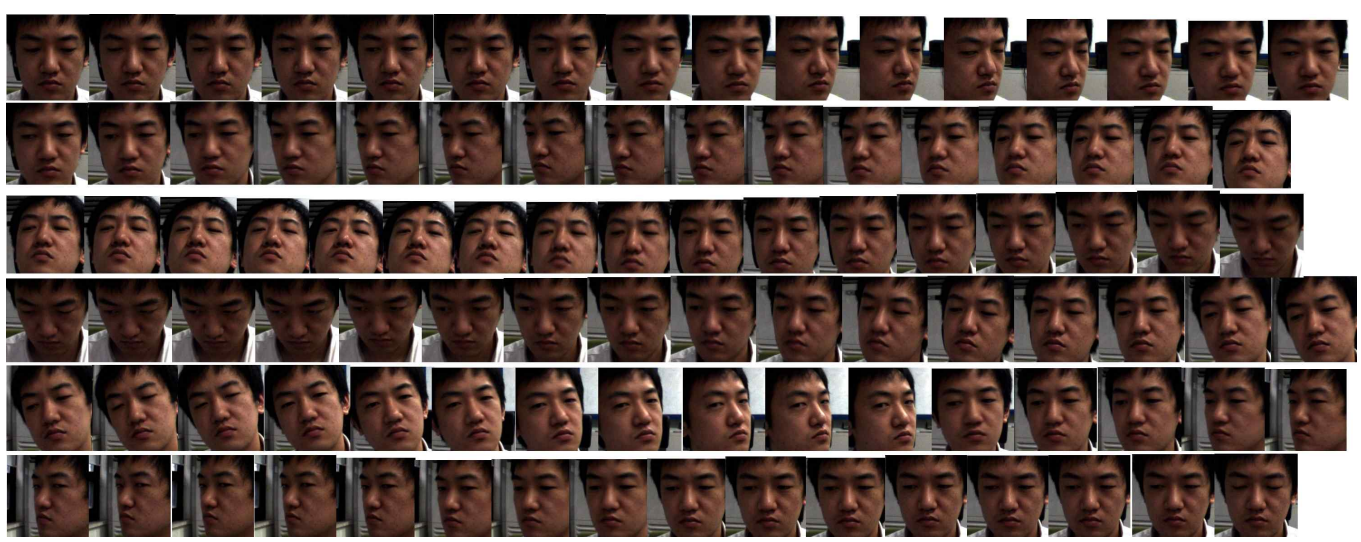

그림 7. 얼굴 추적에 대한 연속 영상 시퀸스

Fig. 7. A continuous face tracking sequence by the proposed algorithm 
느 정도 움직이는 행동을 취했다. 먼저 정확한 성능 비교를 위해 선행 연구 ${ }^{[1]}$ 에서 개발된 방법과 본 논문에서 제안한 방법을 같은 실험영상에 대해 적용했다. 이에 대한 결과는 그림 8 에 나타내었다.

그림 8 의 $\mathrm{x}$ 축은 검출된 얼굴 중심의 좌표로서 $\mathrm{X}, \mathrm{Y}$ 축이

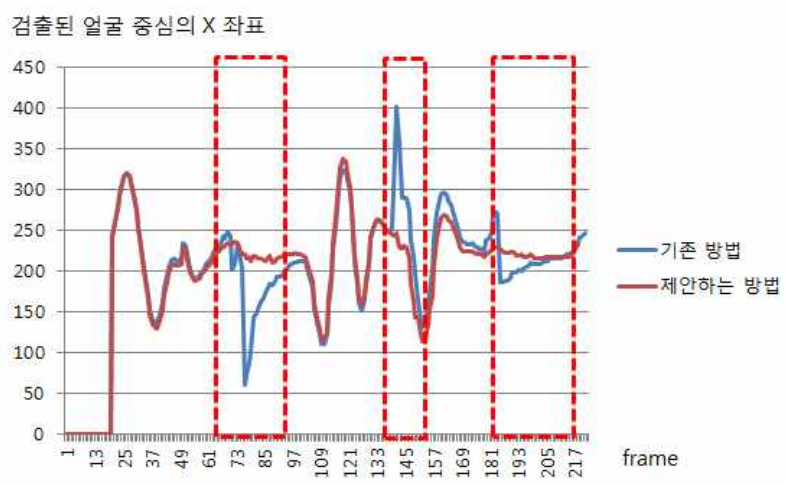

그림 8. 같은 실험영상에 대한 두 방법의 얼굴 검출 결과 비교.

Fig. 8. Comparing results of the previous work and the proposed method
동일한 경향성을 가지므로 X축 방향의 중심만을 표시했다. 빨간 점선으로 표시된 영역은 밝기값이 급격하게 변하는 구간으로 이 구간에서 기존 방법과 제안하는 방법이 차이 가 나는 것을 확인 할 수 있다. 피실험자의 얼굴이 거의 고 정되어 있음에도, 기존의 방법 ${ }^{[1]}$ 의 경우 잘못된 옵티컬-플 로우의 결과를 그대로 최종 결과에 반영해 잘못된 얼굴 추 적 결과를 도출하는 모습을 보이는 반면 제안하는 알고리 즘은 조명 변화에 의한 옵티컬-플로우가 잘못됨으로 인해 $\alpha$ 값을 0 으로 함으로써 옵티컬-플로우의 결과를 배제함으 로써 안정적으로 고정된 얼굴을 검출하고 추적하는 것을 확인 할 수 있다. 그림 9는 두 가지 알고리즘의 실제 얼굴 검출 결과를 보여주고 있다. 그림에서 보면 조명환경에 따 라 본 논문에서 제안하는 방법이 매우 안정적으로 얼굴을 검출하고 추적하는 결과를 보여주는 것을 확인할 수 있다.

그림 10(a), (b)는 III.1에서 밝힌 옵티컬-플로우 추적의 실패에 대한 판별식 (3)과 (4)의 조건에 대한 검증 결과이 다. 그림 $10(\mathrm{a})$ 는 식 (3)의 조건 중 $\left|\mathrm{v}_{i}\right|<$ threshold 만에
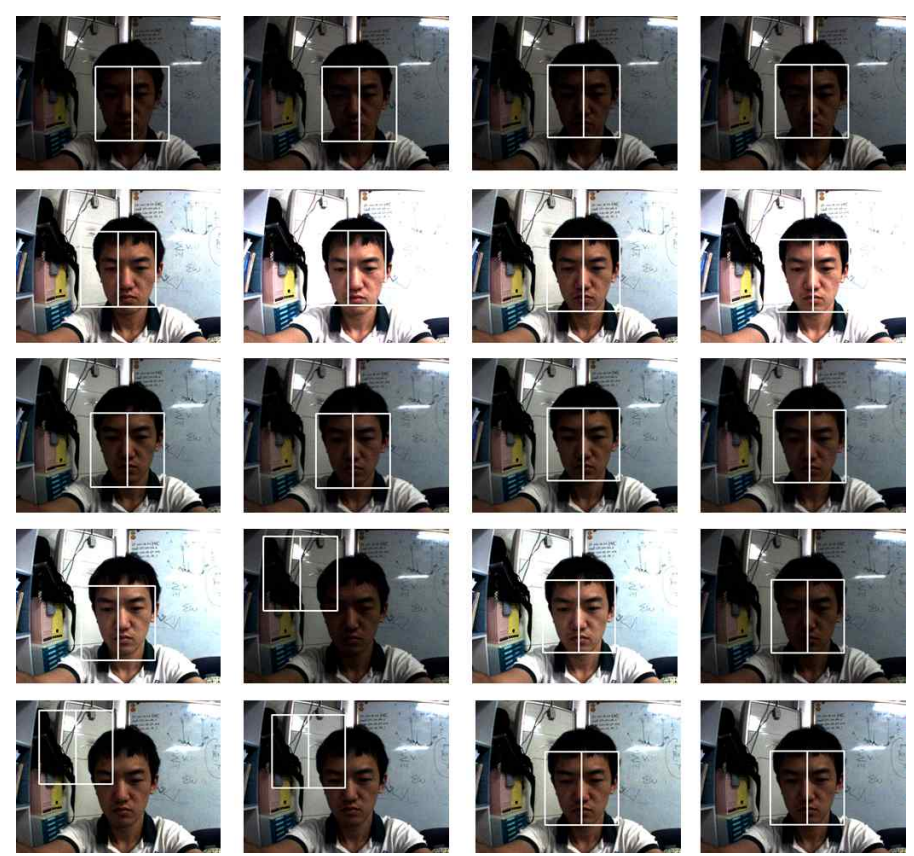

(a) 기존 방법[1]

(b) 새롭게 제안한 방법

그림 9. 조명이 급격하게 변하는 환경에서 얼굴 검출 결과 비교

Fig. 9. Comparison of the previous[1] and the proposed face detection in sudden illumination changes 


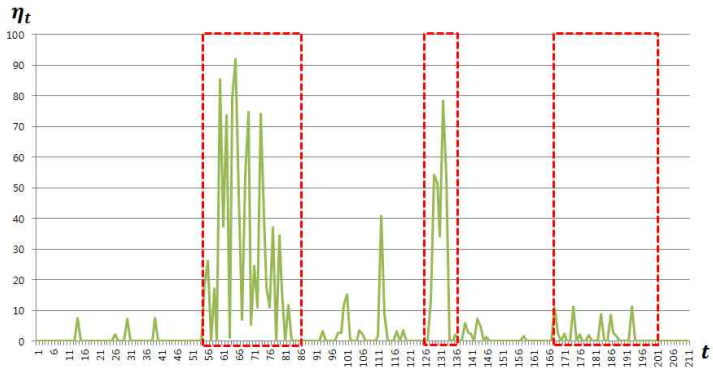

(a) 벡터의 크기만 조건으로 적용한 경우

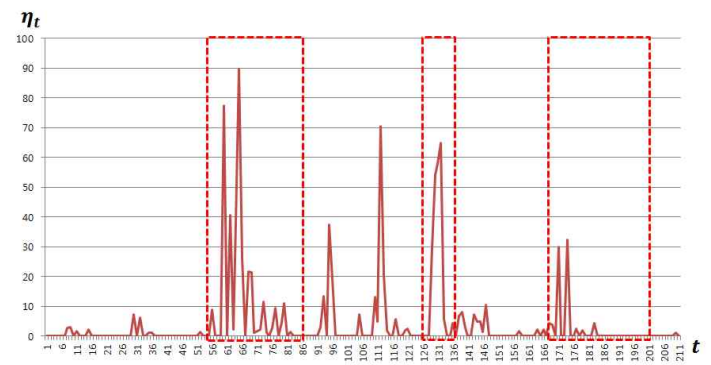

(b) 얼굴 영역만 조건으로 활용한 경우

그림 10. 화면의 밝기가 급격하게 변화하는 테스트 비디오 시퀀스에 대한 다양한 옵티컬-플로우 얼굴추적 실패율 $\left(\eta_{t}\right)$ 측정 결과

Fig. 10. Detection failures by the optical-flow method in sudden illumination changes in case of (a) only using vector magnitude and (b) only using the face region.

해당하는 벡터만 실패 $\left(f\left(\mathrm{v}_{i}\right)=0\right)$ 로 간주했을 때의 전체 옵티컬-플로우 실패율 $\eta_{t}$ 을 프레임별로 나타낸 것이다. 옵티컬-플로우의 실패율이 밝기가 급격하게 변하는 구간 에서 다른 구간보다 높은 특징으로 나타나는 것을 통해, 벡터의 크기만을 이용해 옵티컬-플로우에 의한 특징점 추 적에 대한 성공과 실패를 판단하는 것도 의미가 있음을 알 수 있다. 그림 $10(\mathrm{~b})$ 는 옵티컬-플로우 결과의 특징점 에 대해 $B_{i} \in$ Face Region 조건만 적용했을 때의 실패율 $\left(\eta_{t}\right)$ 그래프이다. 그리고 그림 4는 식 (3)과 같이 벡터의 크 기와 얼굴 영역 두 조건 모두를 만족하는 경우만 추적에 성공한 특징점으로 판단했을 때의 결과이다. 이러한 실험 결과들을 통해 본 논문에서 제안하는 옵티컬-플로우의 특 징점 추적에 대한 실패율 식 (3)과 (4)의 조건이 매우 유효

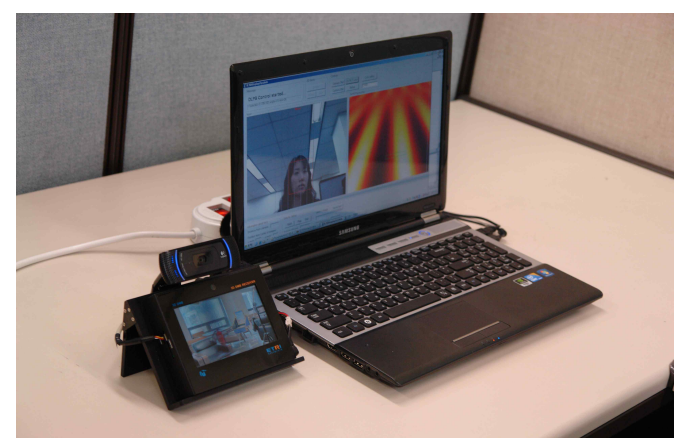

그림 11. 이동형 패럴랙스 배리어 3D 모바일 디스플레이 시제품 실험 장치

Fig. 11. A prototype of moving parallex 3D mobile display
함을 확인할 수 있다. 그리고 본 논문에서 개발된 시역계측 알고리즘을 그림 11 에 보인 시제품에 직접 구현하여 실험 한 결과는 이전 연구에서 개발한 시역계측 알고리즘보다 매우 안정적이고, 급격한 조명 변화에도 문제없이 잘 동작 함을 확인하였다.

\section{V. 결 론}

본 논문에서는 이동형 패럴랙스 배리어 $3 \mathrm{D}$ 모바일 디스플 레이에 응용하기 위한 강인한 시역 계측 알고리즘을 제안하 였다. 선행 연구[1]에서 나타났던 급격한 밝기 변화에 대한 옵티컬-플로우 추적기의 문제점을 먼저 분석하였다. 기존의 방법은 조명이 급격하게 변하는 상황에서 옵티컬-플로우에 의한 특징점 추적이 어렵고, 잘못된 결과를 도출한다는 것을 파악하였다. 옵티컬-플로우의 잘못된 추적 결과에 영항을 받 지 않기 위해 옵티컬-플로우 추적 실패를 판단할 수 있는 새 로운 방법을 제안하였고, 이를 이용하여 최종적인 얼굴 검출 결과에 반영함으로써 얼굴 검출 성능을 개선할 수 있었다.

특히, 제안된 알고리즘은 실험결과에서 조명의 밝기가 급 격하게 변화하는 상황에서도 안정적으로 얼굴을 검출할 수 있었다. 제안된 알고리즘의 이러한 특징을 이용한다면, 모바 일 단말을 시청할 때 조명 환경과 같은 외부 요인의 변화에 강인한 시점 추적이 가능하게 된다. 그리고 개발된 시역 계측 알고리즘은 한국전자통신연구소(ETRI)에서 제작한 실제 $3 \mathrm{D}$ 모발 디스플레이 시제품에 구현하여 그 효용성을 검증하였다. 


\section{참 고 문 헌}

[1] G. Kim, J. S. Cho, "Study on Viewpoint Estimation for Moving Prallax Barrier 3D Display" Journal of Institute of Control, Robotics and Systems, vol. 18, no. 1, pp. 7-12, 2012. 1.

[2] H. Lee, E. D. Lee, and G. M. Um, "Autostereoscopic Display based on Dual Layer Parallax Barrier" Journal of the Institute of Electronics Engineers of Korea, vol. 48, no. 6, pp. 816-823, 2011. 11.

[3] Paul Viola and Michael Jones, "Robust Real-time Object Detection,"
International Journal of Computer Vision (IJCV), 2004.

[4] B. D. Lucas and T. Kanade, "An iterative image registration technique with an application to stereo vision," Proceeding of the 1981 DARPA Imaging Understanding Workshop pp.121-130, 1981.

[5] Jianbo Shi, Tomasi, C., "Good features to track", 1994 IEEE Computer Society Conference on, pp.593-600, 1994.

[6] G. Kim, J. S. Cho. K. Jung, E. D. Lee, and W. S. Cheong "Robust Face Detection and Tracking Algorithm for Sudden Changes of Illumination” 2011 JBE Autumn Conference on, 2011. 11.

저 자 소 개

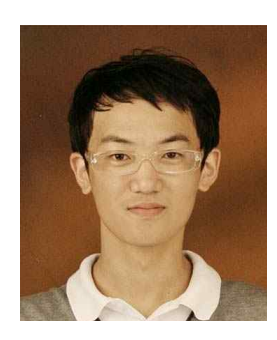

김 기 석

- 2010년 2월 : 한국기술교육대학교 인터넷 공학과(공학사)

- 2012년 8월 : 한국기술교육대학교 컴퓨터공학과(공학석사)

- 현재 : 한국기술교육대학교 컴퓨터공학과 박사과정

- 주관심분야 : Object Tracking, Programming Language

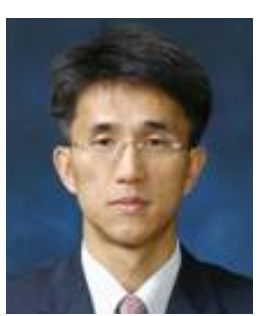

조 재 수

- 1993년 2월 : 경북대학교 전자공학과(공학사)

- 1996년 2월 : 한국과학기술원 전기 및 전자공과(공학석사)

- 2001년 2월 : 한국과학기술원 전기 및 전자공학(공학박사)

- 2001년 3월 2003년 7월 : (주삼성전자

- 2003년 9월 현재 : 한국기술교육대학교 컴퓨터공학부 부교수

- 주관심분야 : Automatic Video Tracking, Visual Surveillance, Pattern Recognition, Machine Learning

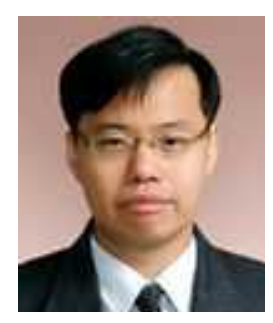

\section{엄 기 문}

- 1991년 : 서강대학교 전자공학과(공학사)

- 1993년 : 서강대학교 전자공학과공학석사)

- 1998년 : 서강대학교 전자공학과(공학박사)

- 2000년 현재 : 한국전자통신연구원(ETRI) 책임연구원

- 2001년 2002년 : 캐나다 CRC(Communications Research Center) 방문연구원

- 주관심분야 : 컴퓨터 비젠, 다시점 $3 \mathrm{DTV}$, 휴먼팩터 